\title{
Elder Abuse and Lawyers' Ethical Responsibilities: \\ Incorporating Screening into Practice
}

\author{
Nola M Ries \\ Associate Professor \\ Law | Health | Justice Research Centre \\ Faculty of Law, University of Technology Sydney \\ PO Box 123, Broadway NSW 2007 Australia \\ T:+6195143156 E: nola.ries@uts.edu.au
}

The published version of the manuscript appears in Legal Ethics, 2018, volume 21, issue 1, pages

23-45, doi: https://doi.org/10.1080/1460728x.2018.1502965.

\begin{abstract}
Elder abuse is a serious and under-detected problem. Law reform agencies and legal profession regulatory authorities have called for action to ensure that lawyers meet their ethical obligations to older clients, including identifying and acting on risk factors for abuse. Screening tools to detect situations of elder abuse exist, but they are targeted mainly at health and social care practitioners. Drawing on international literature, this article identifies and discusses screening tools that could be adapted for use by legal professionals. Three general categories of screening are relevant for lawyers who serve older clients: (1) elder abuse screening tools that cover all domains of abuse or target specific behaviours, such as financial exploitation; (2) screening for decision-making capacity, especially taking account of the impact of abuse or neglect on capacity; and (3) screening to probe the suitability of a person to act in a formal decision-making role for an older person. The article emphasises the importance of implementing screening processes and follow-up actions in a manner that fosters a therapeutic relationship between the older client and the lawyer. It concludes with recommendations for further research in this important area.
\end{abstract}




\section{Introduction}

The abuse and exploitation of older people is emerging as a profound problem that demands attention and action. Around the world, it is estimated that every year, nearly one in six older people living in a community setting experiences abuse, ${ }^{1}$ which is defined as 'a single, or repeated act, or lack of appropriate action, occurring within any relationship where there is an expectation of trust which causes harm or distress to an older person.'2 Elder abuse includes physical, psychological and sexual harms, neglect, and financial exploitation. Family members are often the perpetrators and elder abuse has been

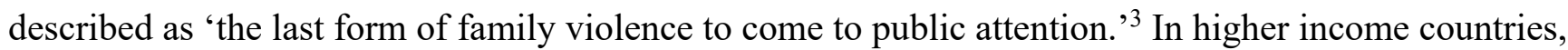
financial and psychological forms of abuse are estimated to be the most prevalent, followed by physical abuse, neglect and sexual abuse. ${ }^{4}$ Under-detection and under-reporting of abuse are serious problems, with only around 1 in 24 situations of abuse being reported. ${ }^{5}$ The global problem of elder abuse will be exacerbated due to ageing populations ${ }^{6}$ and with the increasing number of older people living with chronic health conditions, impaired cognition and physical frailty that heighten their vulnerability to abuse.

\footnotetext{
${ }^{1}$ Yongjie Yon and others, 'Elder Abuse Prevalence in Community Settings: A Systematic Review and Meta-Analysis' (2017) 5 Lancet Global Health 147.

${ }^{2}$ World Health Organization, Elder Abuse - Fact Sheet (September 2016). See

$<\mathrm{http}: / /$ www.who.int/mediacentre/factsheets/fs357/en/>. There is contestation over the term 'elder abuse' and some writers refer instead to maltreatment of older people. Consistent with the majority of published literature on the topic, this article uses the term 'elder abuse' but acknowledges that abuse takes many forms and should not be viewed as a monolithic phenomenon. For discussion, see eg Shelly L Jackson and Thomas L Hafemeister, Understanding Elder Abuse: New Directions for Developing Theories of Elder Abuse Occurring in Domestic Settings. (Research in Brief, National Institute of Justice, June 2013).

${ }^{3}$ Parliament of New South Wales, General Purpose Standing Committee No. 2. Elder Abuse in New South Wales. June 2016. See $<$ https://www.parliament.nsw.gov.au/committees/inquiries/Pages/inquiry-details.aspx?pk=2387\#tab-reports $>$ [NSW Elder Abuse Inquiry], quoting Professor Susan Kurrle, 6, [2.4].

${ }^{4}$ Yon and others, 'Elder Abuse Prevalence in Community Settings' (n 1).

${ }^{5}$ Chiara Gallione and others, 'Screening Tools for Identification of Elder Abuse: A Systematic Review' (2017) 26(15-16) Journal of Clinical Nursing 2154. Perpetrators admit to higher rates of abuse than the number of cases detected by health professionals. See eg Claudia Cooper and others, 'The Sensitivity and Specificity of the Modified Conflict Tactics Scale for Detecting Clinically Significant Elder Abuse’ (2009) 21(4) International Psychogeriatrics 774.

${ }^{6}$ See eg Australian Government, 2015 Intergenerational Report - Australia in 2055,

$<$ http://www.treasury.gov.au/PublicationsAndMedia/Publications/2015/2015-Intergenerational-Report> 5, 7 and 8.
} 
Lawyers who assist older clients, especially with matters such as enduring appointments for financial, health and other personal matters, property transactions, and preparing wills, are in a position to identify clients at risk for or experiencing abuse. Lawyers who fail to meet their ethical duties to older clients can enable abuse and exploitation to occur. In Australia, for example, recent governmental inquiries into elder abuse have criticised lawyers for 'actively unethical practices ${ }^{77}$ that facilitate abuse as well as failing to recognise and act on warning signs that a client is at risk of or experiencing abuse. ${ }^{8}$

Submissions to these inquiries described situations where lawyers 'seriously in breach of their ethical and professional conduct standards ... sanctioned elder abuse against an older client. ${ }^{, 9}$ Regulatory bodies are handling a growing number of complaints about lawyers' conduct, especially in relation to failing to identify situations of coercion and impaired decision-making capacity. ${ }^{10}$ To fulfil their ethical duties, lawyers must act with 'great care and consideration in dealing with older clients' ${ }^{11}$ and '[a] prudent solicitor, when he or she sees the red light, makes enquiries.' ${ }^{12}$

This article proposes the use of screening tools to assist lawyers in meeting their ethical duties to older clients. Lawyers' ethical obligations require that they understand risk factors for and warning signs of abuse, are able to ask appropriate questions to probe for these issues, can advise older clients on preventive strategies to protect themselves from abuse, and can provide clients with information and supports to make decisions based on their interests and values. With examples from the author's Australian context, the article discusses lawyers' ethical duties that are relevant to identifying older clients at risk of or experiencing abuse and responding to situations of concern. ${ }^{13}$ As a prudent lawyer

\footnotetext{
${ }^{7}$ NSW Elder Abuse Inquiry, (n 3) 103, [7.2].

${ }^{8}$ NSW Elder Abuse Inquiry, (n 3) 117. Australian Law Reform Commission. Elder Abuse - A National Legal Response (ALRC Report 131) 2017. See < https://www.alrc.gov.au/publications/elder-abuse-report> [ALRC Elder Abuse Report]. ${ }^{9}$ Ibid, 290.

${ }^{10}$ Office of the Legal Services Commission (NSW), 2013-14 Annual Report. See

$<$ http://www.olsc.nsw.gov.au/Documents/2013_2014\%20annual\%20report\%20accessible.pdf $>, 18$.

${ }^{11}$ Ibid.

${ }^{12}$ Young CJ Yaktine v Perpetual Trustees Victoria Ltd [2004] NSWSC 1078.

${ }^{13}$ This article focuses particularly on New South Wales, which is Australia's most populous state and has the greatest proportion (over 40\%) of legal practitioners in the country. See Law Council of Australia, 'How Many Lawyers are there in Australia?’ <https://www.lawcouncil.asn.au/resources/faqs/how-many-lawyers-are-there-in-australia>.
} 
must 'make enquiries', strategies are proposed for screening and assessing clients in three key areas. First, specific screening tools for elder abuse are identified that could be adapted for use by lawyers. Second, screening for impaired decision-making capacity is discussed. Lawyers should be aware of a vicious circle in relation to abuse and capacity: clients with conditions that affect their cognition are at greater risk of abuse and being victimised by abuse can negatively affect cognitive abilities. Lawyers therefore need to probe both issues where warning signs exist. Third, the use of screening tools is proposed to help clients consider the suitability of a person to be appointed as a decision maker for their financial, health and other personal matters. Of course, screening tools alone will not prevent abuse; rather, they are resources to be used to initiate conversations, ensure relevant topics are covered, and help identify situations where further action may be warranted. Care must be taken to implement screening processes and follow-up actions in a manner that fosters a therapeutic relationship between the older client and the lawyer: clients must feel supported and safe, and their strengths, wishes and preferences must be brought to the fore. Finally, the article offers recommendations for research to implement and evaluate the use of screening tools in legal practice settings, with particular attention to eliciting the views and experiences of older people who must be at the centre of strategies to detect and act on elder abuse in our communities. ${ }^{14}$

\section{Elder Abuse and Lawyers' Ethical Duties}

Elder abuse is not a single phenomenon, rather 'it consists of actions and inactions highly diverse in their origins, nature, and context. ${ }^{15}$ Abuse takes many different forms and involves various risk factors. Impaired cognitive capacity, social isolation, depression and a family history of abuse and interpersonal violence heighten vulnerability. Different forms of abuse are often experienced at the same time and attempts to stop one type of abuse - such as speaking up about financial exploitation - can trigger

\footnotetext{
${ }^{14}$ John Chesterman, 'Taking Control: Putting Older People at the Centre of Elder Abuse Response Strategies' (2016) 69(1) Australian Social Work 115.

${ }^{15}$ Joan R Harbison and others, Contesting Elder Abuse: Ageism, Risk and the Rhetoric of Rights in the Mistreatment of Older People (Vancouver, UBC Press, 2016), 5.
} 
physically and psychologically abusive responses. ${ }^{16}$ Emerging evidence suggests that older women and men are equally at risk of experiencing abuse. ${ }^{17}$ Elder abuse in its various forms has serious individual and social impacts, causing emotional and physical suffering and putting older people at increased risk of injury, hospital admission, placement in residential aged care facilities and premature mortality. ${ }^{18}$ Financial abuse can deprive older people of their retirement savings and pension resources and result in loss of home ownership.

A number of factors hinder both the identification of elder abuse and action to address it. Abuse is often hidden from view, especially for socially isolated older people where the abuser is a family member or carer. ${ }^{19}$ Older people may not identify certain behaviours as abuse, ${ }^{20}$ but the majority of those who experience physical abuse alone or in combination with financial exploitation likely recognise the problem behaviour. ${ }^{21}$ Yet they may be reluctant to disclose the situation due to embarrassment, shame, fear of abuser retaliation, and the desire to maintain caregiving relationships. ${ }^{22}$ Teresi and colleagues caution that '[d]isrupting that [caregiving] dyad or removal of a person from their living arrangement may have deleterious effects. ${ }^{23}$ Family preservation and avoiding placement in institutional care are often very important for older people. ${ }^{24}$ Particular barriers to dealing with elder abuse arise for

\footnotetext{
${ }^{16}$ Tony Rosen and others, 'Acute Precipitants of Physical Elder Abuse: Qualitative Analysis of Legal Records from Highly Adjudicated Cases’ (2016) Journal of Interpersonal Violence 1.

${ }^{17}$ Yon and others, 'Elder Abuse Prevalence in Community Settings' (n 1), report (at 153) that there is 'growing evidence for gender symmetry in abuse victimization.'

${ }^{18}$ XM Wang, X Brisbin, T Loo and S Straus, 'Elder Abuse: An Approach to Identification, Assessment and Intervention' (2015) 187(8) Canadian Medical Association Journal 575.

${ }^{19}$ Shelly L Jackson and Thomas L Hafemeister, 'The Impact of Relationship Dynamics on the Detection and Reporting of Elder Abuse Occurring in Domestic Settings' (2015) 28(2) Journal of Elder Abuse 121.

${ }^{20}$ Corina Naughton and others, 'The Relationship Between Older People's Awareness of the Term Elder Abuse and Actual Experiences of Elder Abuse’ (2013) 25(8) International Psychogeriatrics 1257.

${ }^{21}$ Shelly L Jackson and Thomas L Hafemeister, 'How Case Characteristics Differ Across Four Types of Elder Maltreatment: Implications for Tailoring Interventions to Increase Victim Safety’ (2014) 33(8) Journal of Applied Gerontology 982.

${ }^{22}$ David Burnes, 'Community Elder Mistreatment Intervention with Capable Older Adults: Toward a Conceptual Practice Model' (2017) 57(3) Gerontologist 409.

${ }^{23}$ Jeanne A Teresi and others, 'State of the Science on Prevention of Elder Abuse and Lessons Learned from Child Abuse and Domestic Violence Prevention: Toward a Conceptual Framework for Research' (2016) 28(4-5) Journal of Elder Abuse \& Neglect 263, 277.

${ }^{24}$ Campbell Killick and others, 'Older People's Conceptualization of Abuse: A Systematic Review' (2015) 27(2) Journal of Elder Abuse and Neglect 100. See also Therese Zink and others, 'Older Women's Descriptions and Understandings of Their Abusers' (2006) 12(9) Violence Against Women 851, who report (at 861) that 'older women are often committed to
} 
marginalised and underserved populations who may have limited access to professional advisors and who may lack trust in service providers. ${ }^{25}$

The complexity of elder abuse requires cross-sectoral approaches to identify and assist older people at risk for and experiencing abusive situations. The coordinated involvement of health, legal and community service providers is considered the 'gold standard for programs, policies, and practices, as no single discipline or sector alone has the resources or expertise needed to address the issue. ${ }^{26}$ In Australia, recent federal and state inquiries on elder abuse have stressed the need for 'a much stronger and more comprehensive approach to elder abuse that will engage the whole community with a new focus on prevention. ${ }^{27}$ A whole-of-community approach means that service providers who come into contact with older people have an important role to play in identifying and responding to abuse situations. Lawyers have a vital role since '[o]lder adults who are receiving legal services may be in a help-seeking mode ${ }^{28}$ and there is a prime opportunity for lawyers to identify clients in situations of concern and provide appropriate information and supports.

\section{Lawyers' ethical duties}

Lawyers 'have ethical duties to the court, their clients and to the administration of justice to ensure that the interests of their clients are promoted and protected at all times. ${ }^{29}$ In addition, lawyers 'are

\footnotetext{
continuing the abusive relationship because of generational mores and additional limitations associated with their largely domestic roles.'

${ }^{25}$ Analysis of the unique needs of these groups is beyond the scope of this paper, however, for discussion, see eg Lori L Jervis and others, 'Elder Mistreatment in Underserved Populations: Opportunities and Challenges to Developing a Contemporary Program of Research' (2016) 28(4-5) Journal of Elder Abuse and Neglect 301; Jenny Ploeg, Lynne Lohfeld and Christine AWalsh, 'What Is "Elder Abuse"? Voices From the Margin: The Views of Underrepresented Canadian Older Adults' (2013) 25(5) Journal of Elder Abuse and Neglect 396; AH Grossman and others, 'Domestic Harm and Neglect among Lesbian, Gay, and Bisexual Older Adults' (2014) 61(12) Journal of Homosexuality 1649.

${ }^{26}$ Janice Du Mont and others, 'Determining Possible Professionals and Respective Roles and Responsibilities for a Model Comprehensive Elder Abuse Intervention: A Delphi Consensus Survey' (2015) 10(12) PLoS One e0140760.

${ }^{27}$ NSW Elder Abuse Report (n 3), xi

${ }^{28}$ Sheryl M Strasser and others, 'Screening for Elder Mistreatment among Older Adults Seeking Legal Assistance Services' (2013) 14(4) Western Journal of Emergency Medicine 309, 313.

${ }^{29}$ Law Society of New South Wales, A Practical Guide for Solicitors: When a Client's Mental Capacity is in Doubt (Law Society of New South Wales, 2016). See:

$<$ https://www.lawsociety.com.au/cs/groups/public/documents/internetcontent/1191977.pdf>, 4.
} 
responsible to [their] community to observe high standards of conduct and behaviour' ${ }^{30}$ and 'to fulfill their professional responsibilities, lawyers rendering advice to older clients should give explicit consideration to maintaining or enhancing the client's psychological well-being. ${ }^{31}$ A central duty is to act only on 'lawful, proper and competent instructions," ${ }^{32}$ which requires the lawyer to ensure that an older client has capacity to give instructions. Even where a client is considered to have capacity to make a particular decision, lawyers must also be alert to the risk that the voluntariness of a client's instructions may be compromised as a result of undue influence and coercion exerted by third parties. ${ }^{33}$

A 2016 New South Wales Parliamentary Inquiry into elder abuse underscored that it:

takes very seriously the allegations that some lawyers unwittingly - and in some cases deliberately - facilitate financial abuse. There is a need for action to improve legal practitioners' assessments of people's mental capacity, and some lawyers also need to devote more time to ensuring that the parties to wills, enduring powers of attorney, contracts of sale and other financial transactions understand the implications of the documents they are about to sign. The evidence before us has highlighted the weighty responsibilities that the law confers on lawyers here, the complex issues of which they should be aware, and the substantial risks of not exercising their duty as carefully as they should. ${ }^{34}$

Case examples highlight situations where diligent screening by the lawyer would have identified red flags about the vulnerability of an older person and further investigations would have disclosed abusive

\footnotetext{
${ }^{30}$ Law Society of NSW, Statement of Ethics. See

$<$ https://www.lawsociety.com.au/ForSolictors/professionalstandards/Ethics/statement_of_ethics/index.htm>.

${ }^{31}$ Dennis P Stolle, 'Professional Responsibility in Elder Law: A Synthesis of Preventive Law and Therapeutic Jurisprudence' (1996) 14 Behavioral Sciences and the Law 459, 460.

${ }^{32}$ Legal Profession Uniform Law Australian Solicitors' Conduct Rules 2015, Rule 8.

${ }^{33}$ Deborah O'Connor, Margaret Isabel Hall and Martha Donnelly, 'Assessing Capacity Within a Context of Abuse or Neglect' (2009) 21(2) Journal of Elder Abuse and Neglect 156. The authors observe (at 166) that 'vulnerability stopping short of incapacity can and does impact apparent choice.' For discussion of undue influence, see eg Winefield $v$ Clarke [2008] NSWSC 882: 'Presumed undue influence may arise from the existence of a relationship where one person has assumed a position of ascendancy or influence over the other person or the other person has reposed trust and confidence in the former, and the former has used that relationship to achieve a transaction in which the first person benefits. In the alternative, actual undue influence may be affirmatively proved based on the circumstances and evidence available. In the case of presumed undue influence the onus will rest on the ascendant or trusted party to rebut the presumption and prove that the transaction was voluntary and the result of a free exercise of will or a well understood decision-making process: Johnson $v$ Buttress (1936) 56 CLR 113.' [27].

${ }^{34}$ NSW Elder Abuse Report (n 3), xv.
} 
and exploitative behaviours by those claiming to act in the interests of the older person. For example, in Irvine v Irvine,${ }^{35}$ a 93 -year-old woman transferred her home for nominal consideration to her nephew and his two children, who were also the beneficiaries of her will. She had no children of her own. The evidence before the Court indicated that the nephew influenced her to transfer the house, stating words to the effect: 'This is no use to me the way it is. I think I should have the place in my own name. I want you to give me the house. Why don't you give the house to me now rather than have me wait until you die?' The aunt agreed, but later said she had not had time to consider the matter. She was referred to a solicitor who was found not to have provided adequate independent legal advice. Ordering that the house be transferred back, the Court stated:

In the whole of the circumstances, the aunt stood, in relation to the nephew, in a position of disadvantage. She thought, at the time of the transfer, that he was the only one of nephews and niece [sic] who would look after her. There was therefore a dependence on her part - a dependence that she could not afford to risk by refusal or questioning that might bring out the "forceful" or "overpowering" side of his nature or cause him to "make trouble". 36

In another case, a solicitor was found negligent for his involvement in a matter where a husband forged his wife's signature to register a new mortgage on their family home. ${ }^{37}$ The husband falsely told the lawyer his wife was dying from cancer and could not be visited. The lawyer conceded there were 'alarm bells' and he should have made further enquiries that would have protected the wife from being a victim

\footnotetext{
${ }^{35}$ Irvine v Irvine [2008] NSWSC 592.

${ }^{36}$ Ibid [50]. In regard to the inadequacy of independent legal advice, the Court stated [42]: The involvement of [the solicitor] cannot, on any view, be seen as having put the aunt into a position where she had received adequate legal advice about the protection of her own interests. The aunt was not given the documents in advance to study at her leisure. Nor did she have an opportunity to consult a solicitor of her choosing at a time of her choosing. She was put by the nephew into a position where a person she apparently did not know was a solicitor spent ten minutes talking with her about the documents which she was then asked to sign on the spot.

${ }^{37}$ Graham v Hall \& 1 Or [2006] NSWCA 208. The judgment states [21]: ... [the solicitor] had conceded that, when acting for [the wife] in regard to the mortgage transaction, he heard "alarm bells". This was because he knew that [the husband] had a propensity for bad management of his business and had had difficulty in the past in paying his debts. Moreover, [the solicitor] had been told that [the wife] was dying of cancer but nevertheless was about to enter into a refinancing of the mortgage as a consequence of [the husband's] business debts. Another cause for concern was that, after payment of the existing mortgage and some business debts of $\$ 9,000$, the rest of the money advanced was to be paid to [the husband] alone.
} 
of fraud. In a review of court and guardianship tribunal decisions concerning financial abuse, a former Public Trustee for New South Wales remarked: 'Access to appropriate and independent advice is a common thread as are observations about inadequate legal representation and particularly lawyers not standing back and asking the key questions: "should I be wary of what is proposed" and "what more do I need to know." 38

Lawyers clearly have ethical duties to identify and respond to situations where an older client is being abused or exploited, however, the challenge is to develop and use appropriate screening processes to identify these circumstances. The next section proposes practical tools for this purpose. Various screening tools are reported in the literature and the focus here is on brief screening tools designed for use by community-based service providers that do not require specialised training or medical knowledge. ${ }^{39}$ This discussion is guided by the caution that 'lawyers should be very wary of converting themselves into amateur psychologists and should not, for example, try to administer ... tests widely used by medicos and other health professionals trained in their use. ${ }^{40}$ Nonetheless, the case examples noted above demonstrate that improvements are urgently needed to bring greater consistency to lawyers' practices to ensure they ask relevant questions and discuss potential situations of concern with their older clients. Indeed, the legal sector has been criticised for 'gerontological illiteracy,' being unaware of, and failing to draw on, health and social research to develop evidence-informed strategies to deal with elder abuse. ${ }^{41}$ To remedy such illiteracy, this article draws extensively on health-related literature.

\footnotetext{
${ }^{38}$ Peter Whitehead, 'A Review of the Response of the Courts and NSW Guardianship Tribunal to Cases of Financial Abuse' (2008) 6 Elder Law Review.

${ }^{39}$ Lichtenberg and colleagues point out the advantages of such screening tools as being quick to administer, useful in identifying situations of concern, and 'they can be used across more settings by more professionals.' Peter A Lichtenberg and others, 'The Lichtenberg Financial Decision Screening Scale (LFDSS): A new tool for assessing financial decision making and preventing financial exploitation' (2016) 28(3) Journal of Elder Abuse and Neglect 134, 140.

${ }^{40}$ Justice R I Barrett, 'Law Society of New South Wales, Elder Law and Succession Committee, "Listen to the Judges" Series' [2012] New South Wales Judicial Scholarship 34.

${ }^{41}$ Martin Mulroy and Desmond O’Neill, 'Elder Abuse' (2011) 343 British Medical Journal d6027. The authors point out (at $\mathrm{d} 6027$ ) that there has been 'relatively little emphasis on framing elder abuse in terms of broader societal responsibilities outside of health and social care. ... much of the research, methodological development, and training in elder abuse has been developed within the healthcare and social care sector, but a great deal of elder abuse occurs outside of this environment ...
} 


\section{Screening to Improve Detection of Problem Situations}

Identifying and responding to elder abuse involves five stages: (1) noticing relevant signs of abuse; (2) perceiving the situation as a form of abuse; (3) deciding that acting on the situation is within one's scope of responsibility; (4) knowing strategies and options for acting on the situation; and (5) deciding to act. ${ }^{42}$ Barriers for lawyers - and other professionals who interact with older clients - can exist at all these stages and a crucial first step is to improve practitioners' ability to recognise risk factors for or signs of abuse among their older clients. ${ }^{43}$

To improve detection, it has been recommended that screening for abuse should be a routine part of primary healthcare for older people ${ }^{44}$ and, as discussed below, several elder abuse screening tools have been developed for use by community-based health and social care providers. ${ }^{45}$ There are growing calls for legal and financial service providers to engage in screening to enable earlier identification of older clients at risk of or experiencing abuse. ${ }^{46}$ Yet many service providers lack confidence in knowing how to screen for abuse, identifying the tools that are available to guide their conversations with clients, and what to do when screening identifies a problem. ${ }^{47}$ A recent survey of elder law practitioners in the

\footnotetext{
[and] the involvement of the financial, banking and legal sectors is vital. This is challenging because gerontological illiteracy (a failure to adapt policy and practice to advances in the gerontological sciences) is widespread...'

${ }^{42}$ Mary M Gilhooly and others, 'Financial Elder Abuse Through the Lens of the Bystander Intervention Model' (2016) 26 (1) Public Policy \& Aging Report 5.

${ }^{43}$ Priscilla Harries and others, 'Identifying and Enhancing Risk Thresholds in the Detection of Elder Financial Abuse: A Signal Detection Analysis of Professionals' Decision Making' (2014) 14 BMC Medical Education 1044; Jill Manthorpe, Kritika Samsi and Joan Rapaport, 'Responding to the Financial Abuse of People with Dementia: A Qualitative Study of Safeguarding Experiences in England' (2012) 24(9) International Psychogeriatrics, 1461.

${ }^{44}$ Gallione and others, 'Screening Tools for Identification of Elder Abuse' (n 5). Du Mont J and others, 'Development of a Comprehensive Hospital-Based Elder Abuse Intervention: An initial Systematic Scoping Review' (2015) 10(5) PLoS One 10 .

${ }^{45}$ PR Baker and others, 'Interventions for Preventing Abuse in the Elderly' (2016) 28(3) Cochrane Database of Systematic Reviews 134.

${ }^{46}$ ALRC Elder Abuse Report, (n 8). Numerous submission to the ALRC inquiry recommended wider use of elder abuse screening. The submissions are available online: $<$ https://www.alrc.gov.au/inquiries/elder-abuse/submissions $>$. See eg, Social Work Department Redland Hospital, Qld Health, Submission No. 10, 3; Dr Helen Vidler, Submission No. 12, 1; The Old Colonists' Association of Victoria, Submission No. 16, 3; Pauline Klipppmark, Nicholas Morrissey and Matthew Staley, Submission No. 26, 5.2.3; NSW Nurses and Midwifes' Association, Submission No. 29, 29; Law Council of Australia, Submission No. 61, 46; Alzheimers Australia, Submission No. 80, 31; Aged and Community Services Australia, Submission No. 102, 9; Legal Aid NSW, Submission No. 140, 4; Justice Connect, Submission No. 182, 3.

${ }^{47}$ Xi Dong Dong, 'Screening for Elder Abuse in Healthcare Settings: Why Should We Care, and Is It a Missed Quality Indicator? (2015) Journal of the American Geriatrics Society 63(8)1686-1688
} 
United States identified elder abuse and complex ethical issues as frequently encountered issues with a concomitant need for training in areas such as client interviewing and counseling. ${ }^{48}$ Professionals may worry about raising false alarms, especially in jurisdictions with mandatory reporting of elder abuse cases. ${ }^{49}$ However, '[p]rofessional judgement in this area involves balancing the need to risk false alarms with the risk of allowing abuse to continue unchecked. ${ }^{50}$

In the legal services context, some previous work has recommended that general practice lawyers use a 'diagnostic triage and referral' approach to identify and prioritise clients' legal needs and assess their capabilities to understand and act on their legal rights. ${ }^{51}$ This approach could be beneficial in the context of screening for elder abuse, as well as assessing an older client's decision-making capacity. Where problems are identified, the lawyer could work with the client to seek specialist supports from elder law experts, geriatric health professionals, and, where appropriate police or adult protective services.

However, lawyers need practical resources, such as screening tools, to use in this process. An Australian study that involved interviews with lawyers found that approaches to assessing clients' needs and capabilities were subjective, ad hoc and based on gut feelings. ${ }^{52}$ It recommended standardised practices to screen clients and assist with intake, triage and referrals. A recent disciplinary case highlights the problem with ad hoc approaches. In taking instructions from a 76-year-old client with impaired memory, a lawyer recounted that 'we had social chitchat and we had legal chitchat about the contents of his will

\footnotetext{
${ }^{48}$ Nina A Kohn and Edward D Spurgeon, 'A Call to Action on Elder Law Education: An Assessment and Recommendations Based on a National Survey’ (2014) 21 Elder Law Journal 345.

${ }^{49}$ Harries and others, 'Identifying and Enhancing Risk Thresholds in the Detection of Elder Financial Abuse', (n 43), points out that practitioners may fear making a 'mistaken claim [that] can lead to reprimands from employers and rejection by clients.' (at 1045)

${ }^{50}$ Ibid.

${ }^{51}$ Pascoe Pleasance and others, Reshaping Legal Assistance Services: Building on the Evidence Base (2014) Law and Justice Foundation of New South Wales Discussion Paper. See $<$ http://www.lawfoundation.net.au/ljf/site/articleIDs/D76E53BB842CB7B1CA257D7B000D5173/\$file/Reshaping_legal_ass istance_services_web.pdf $>$. Legal capability is defined (at 35) as referring 'to the personal characteristics or competencies (knowledge, skills, psychological, resources) needed to effectively resolve legal problems.' See also Hugh M McDonald and Zhigang Wei, 'How People Solve Legal Problems: Level of Disadvantage and Legal Capability' (2016) Paper 23, Justice Issues, Law and Justice Foundation of New South Wales.

${ }^{52}$ Pleasance and others, Reshaping Legal Assistance Services, (n 51), 156
} 
and the power of attorney that weren't all yes and no answers, but I can't actually remember what we discussed. I can't remember those questions and answers... ${ }^{53}$

Australian legal disciplinary tribunals have noted the value of tools that guide practitioners through structured approaches to ensure thorough inquiries are made. ${ }^{54}$ Research on Community Legal Advice Centres in the UK reported that 'standard checklists and questionnaires were regarded as being useful ... because they provided a structured way to gather information from clients. ${ }^{55}$ Moreover, where a lawyer has a continuing relationship with a client, standardised tools allow for the same questions to be asked of the person over time, allowing for comparison and detection of changes in responses that may indicate the emergence of problems.

This article recommends that the legal profession invests in strategies to implement and evaluate the use of screening tools by lawyers who work with older clients to improve processes to identify and act on signs of and risk factors for abuse: 'Interventions that can heighten sensitivity to the recognition of abuse ... could be expected to lead to a more appropriate, heightened action response. ${ }^{56}$ In support of this recommendation, the following section presents several screening strategies and identifies screening tools that could be adapted for use by legal professionals as they are quick to administer, designed for community settings, and do not require specialised expertise.

\footnotetext{
${ }^{53}$ Legal Services Commissioner v Given [2015] QCAT 225 (President Thomas), para 58. The older client had separated from his wife of many years and an aged care services assessment determined him to require a high level of care. Accompanied by his sister, with whom he now lived, the client saw the solicitor to appoint the sister as enduring power of attorney and to change his will to exclude his wife and leave his estate to his sister's children. The Tribunal found the solicitor fell below a reasonable standard of competence and diligence. The Tribunal stressed the need for appropriate questioning and thorough note-keeping to document how inquiries were made concerning the client's health and personal circumstances and capacity to give instructions. On the importance of through inquires and note-keeping, see also Legal Services Commissioner v Penny [2015] QCAT 108 and Legal Services Commissioner v de Brenni [2011] QCAT 340

${ }^{54}$ Legal Services Commissioner v Penny [2015] QCAT 108. The Tribunal cited capacity guidelines issued by the Public Guardian and noted (at [39]) that such 'guidelines set out important methodologies which assist in ensuring that the client is aware of the meaning of the document.' Elder abuse screening tools have similar benefits in probing the client's circumstances for signs of abuse.

${ }^{55}$ Pleasance and others, Reshaping Legal Assistance Services, (n 51), 150.

${ }^{56}$ Priscilla Harries and others, 'Identifying and Enhancing Risk Thresholds in the Detection of Elder Financial Abuse: A Signal Detection Analysis of Professionals' Decision Making' (2014) 14 BMC Medical Education 1044, 1046.
} 


\section{Screening Strategies}

Elder abuse screening tools provide questions that can be used to flag or rule out situations of concern. As Gallione and colleagues state: 'The fundamental function of any assessment instrument is to guide through a standardised screening process and to ensure that signs of abuse are not missed. ${ }^{57}$ Such tools can increase practitioners' confidence in asking relevant questions and collecting consistent information from their older clients to inform tailored advice and supports. To be useful, screening tools need to be valid, reliable, sensitive and specific. ${ }^{58}$ Validity means that the tool actually measures or predicts what it claims to do and reliability means that it consistently measures what it claims across different people and settings. Sensitivity means that a screening tool detects the issue of concern among people experiencing it and specificity means a test or tool rules out people not experiencing the problem. In screening, strong sensitivity and specificity avoids false-positives and false-negatives. Where screening questions identify risk factors for abuse or actual harm, further and more specific discussion is warranted.

Three general categories of screening are relevant for lawyers who serve older clients: (1) elder abuse screening tools that cover all domains of abuse or target specific types, such as financial exploitation; (2) screening for capacity, especially taking account of the impact of abuse or neglect on decisionmaking; and (3) screening to probe the suitability of a person to act in a formal decision-making role for an older person.

\section{Elder abuse screening tools}

\footnotetext{
${ }^{57}$ Gallione and others, 'Screening Tools for Identification of Elder Abuse' (n 5), 1.

58 The psychometric strength of the elder abuse tools discussed here continue to be studied, especially by researchers who are adapting the tools into languages for use in cultural contexts different to the original setting. See eg Raquel Batista Dantas, Graziella Lage Oliveira and Andréa Maria Silveira, 'Psychometric Properties of the Vulnerability to Abuse Screening Scale for Screening Abuse of Older Adults' (2017) 51 Revista de Suade Publica 31; Amanda Phelan and Margaret P Treacy, A Review of Elder Abuse Screening Tools for Use in the Irish Context (2011), University College Dublin. See $<$ http://www.ncpop.ie/userfiles/file/ncpop\%20reports/538_NCPOP-proof7.pdf>.
} 
The Elder Abuse Suspicion Index ${ }^{\odot}$ (EASI), originally developed in Canada, has six questions, can be completed in a few minutes, and has high specificity, meaning it is effective in ruling out situations of abuse.$^{59}$ It covers all types of abuse and asks about reliance on others as a risk factor for abuse as well as actual experiences of abusive conduct. The $\mathrm{EASI}^{\odot}$ has been validated for use in primary healthcare settings to screen older adults who do not have impaired cognition. A World Health Organization working group on elder abuse has validated the content of the EASI questions in seven different countries. ${ }^{60}$

\section{Elder Abuse Suspicion Index ${ }^{\odot}$}

In the last 12 months:

1. Have you relied on people for any of the following: bathing, dressing, shopping, banking or meals?

2. Has anyone preventing you from getting food, clothes, medication, glasses, hearing aids or medical care, or from being with people you wanted to be with?

3. Have you been upset because someone talked to you in a way that made you feel shamed or threatened?

4. Has anyone tried to force you to sign papers or to use your money against your will?

5. Has anyone made you afraid, touched you in ways that you did not want, or hurt you physically?

6. [For assessment by the practitioner]: Elder abuse may be associated with findings such as: poor eye contact, withdrawn nature, malnourishment, hygiene issues, cuts, bruises, inappropriate clothing, or medication compliance issues. Did you notice any of these today or in the last 12 months?

The Hwalek-Sengstock Elder Abuse Screening Test (HS-EAST) is a 15-item tool designed to help health and community service providers identify people at risk of abuse by asking questions that seek to detect direct abuse or overt violations of an older person's rights, traits of the older person that make

\footnotetext{
${ }^{59}$ Mark J Yaffe and others, 'Development and Validation of a Tool to Improve Physician Identification of Elder Abuse: The Elder Abuse Suspicion Index (EASI)C' (2008) 20(3) Journal of Elder Abuse and Neglect 279. Further information about the tool is available, see $<$ https://www.mcgill.ca/familymed/research/projects/elder $>$.

${ }^{60}$ World Health Organization, A Global Response to Elder Abuse and Neglect: Building Primary Health Care Capacity to Deal with the Problem World-Wide (World Health Organization: Geneva, 2008). See

$<$ http://apps.who.int/iris/bitstream/10665/43869/1/9789241563581_eng.pdf $>$.
} 
them vulnerable to abuse, and features of potentially abusive situations. ${ }^{61}$ It covers all types of abuse and can be completed in five to ten minutes. The HS-EAST was used in pilot study of older adults attending free community legal advice clinics in Atlanta, Georgia, where nearly $30 \%$ of respondents met the criteria for being at risk of elder abuse or neglect. ${ }^{62}$

\section{Hwalek-Sengstock Elder Abuse Screening Test}

The response that indicates a risk factor for abuse is noted at the end of each question.

1. Do you have anyone who spends time with you, taking you shopping or to the doctor? [no]

2. Are you helping to support someone? [yes]

3. Are you sad or lonely often? [yes]

4. Who makes decisions about your life - like how you should live or where you should live? [someone else]

5. Do you feel uncomfortable with anyone in your family? [yes]

6. Can you take your own medication and get around by yourself? [no]

7. Do you feel that nobody wants you around? [yes]

8. Does anyone in your family drink a lot? [yes]

9. Does someone in your family make you stay in bed or tell you you're sick when you know you're not? [yes]

10. Has anyone forced you to do things you didn't want to do? [yes]

11. Has anyone taken things that belong to you without your O.K.? [yes]

12. Do you trust most of the people in your family? [no]

13. Does anyone tell you that you give them too much trouble? [yes]

14. Do you have enough privacy at home? [no]

15. Has anyone close to you tried to hurt you or harm you recently? [yes]

The Vulnerability to Abuse Screening Scale (VASS) was originally developed and tested in Australia as a self-reporting tool to identify older women at risk of abuse and has since been translated and used elsewhere. ${ }^{63}$ It includes questions from the HS-EAST with an additional two: "Has anyone close to you called you names or put you down or made you feel bad recently?" and "Are you afraid of anyone in your family?" It can be completed in five to ten minutes.

\footnotetext{
${ }^{61}$ AN Neale and others, 'Validation of the Hwalek-Sengstock Elder Abuse Screening Test' (1991) 10(4) Journal of Applied Gerontology 406. See

$<$ https://medicine.uiowa.edu/familymedicine/familymedicine/sites/medicine.uiowa.edu.familymedicine/files/wysiwyg_uploa ds/HS_EAST.pdf>.

${ }^{62}$ Sheryl M Strasser and others, 'Screening for Elder Mistreatment among Older Adults Seeking Legal Assistance Services' (n 28).

${ }^{63}$ MJ Schofield and GD Mishra, 'Validity of Self-Report Screening Scale for Elder Abuse: Women's Health Australia Study' (2003) 43(1) The Gerontologist 119; Raquel Batista Dantas, Graziella Lage Oliveira and Andréa Maria Silveira, 'Psychometric Properties of the Vulnerability to Abuse Screening Scale for Screening Abuse of older adults' (2017) 51 Revista de Suade Publica 31.
} 
The Older Adult Financial Exploitation Measure (OAFEM) is the only tool reported in the literature that has been validated to assess specifically for financial abuse issues. ${ }^{64}$ It consists of 25 yes/no questions that cover possible fraud and financial exploitation, victimisation, coercion, and financial management issues. Older people who are being financially exploited are likely to experience a number of the problems covered in the OAFEM. Recent research suggests that the first six questions can be used as a brief screen, with affirmative answers to any of those questions prompting completion of the rest of the questionnaire. ${ }^{65}$ The time required to complete this tool has not been reported.

\section{Older Adult Financial Exploitation Measure}

1. Has someone borrowed money from you but not paid it back?

2. Has someone felt entitled to use your money for him/herself?

3. Has someone used your money on their own behalf instead of for your benefit?

4. Have there been unexplained disappearances of your funds or possessions?

5. Has someone lied about how they were spending your money?

6. Has someone demanded money from you?

7. Did someone take advantage of you to get hold of your resources such as a house, car or money?

8. Has someone given unreasonable explanations for spending your money?

9. Has someone refused to give you an account of how your money was spent?

10. Has someone taken your money to do something for them but never did it?

11. Have your legal or financial documents been frequently changed (e.g, the deeds of your house, your will, insurance policies or share holdings)?

12. Have there been unusual activities in your bank accounts, for example, large withdrawals, frequent transfer of funds?

13. Has someone said they would use your money to buy something for you but it was really for their own use?

14. Has someone handled your money irresponsibility (for example, drink, drugs or gambling?

15. Have there been unauthorized withdrawals from your bank account?

16. Has someone taken advantage of cultural or family expectations to get your resources?

17. Has someone persuaded you to sign any documents even though it was not in your best interest?

18. Has someone manipulated you to give him/her larger than usual gifts (money, cars, homes)?

19. Has someone prevented you from spending your money in order to preserve their inheritance?

20. Has someone promised care for you but then did not provide it?

21. Has someone tricked or pressured you into buying something that you now regret buying?

22. Has someone taken money from your social welfare allowances (i.e. pension) and used the money for him/herself?

23. Has someone convinced you to turn over your home, property, farm, car, etc. to their benefit and not yours?

24. Has someone pressured you to change your will?

25. Has someone changed where your electronic/direct deposit is going to benefit him/herself?

The brief sets of questions presented in these screening tools could assist lawyers in discussing the issue of abuse with their older clients. In addition to identifying and assisting clients who may be vulnerable

\footnotetext{
${ }^{64}$ Kendon J Conrad and others, 'Self-Report Measure of Financial Exploitation of Older Adults' (2010) 50(6) Gerontologist 758.

${ }^{65}$ A Phelan, G Fealy and C Downes, 'Piloting the Older Adult Financial Exploitation Measure in Adult Safeguarding Services' (2017) 70 Archives of Gerontology and Geriatrics 148.
} 
to or experiencing abuse, lawyers must also ensure that clients have capacity to make the decisions that form the basis for their legal instructions.

\section{Capacity screening}

Impaired decision-making capacity increases older clients' risk of abuse and the ethical lawyer must be vigilant to screen for potentially impaired capacity. Legal professional bodies in Australia provide guidance for practitioners on meeting their ethical duties when a client's decision-making capacity is in doubt. ${ }^{66}$ In general, these guidelines discuss warning signs of impaired decision-making capacity, ${ }^{67}$ questioning strategies, such as using open-ended questions and meeting the client alone, and processes for seeking a formal capacity assessment from a medical professional. The guidelines also advise lawyers to be aware that clients living with conditions that impair cognition may be more vulnerable to abuse and exploitation, but do not provide specific screening questions to probe for situations of concern. $^{68}$

The extent to which lawyers are aware of and use these guidelines is unclear, however, various sources report shortcomings in lawyers' practices, including failures to identify and act on warning signs of impaired capacity, inadequate training in interviewing skills, variable approaches to assessing capacity,

\footnotetext{
${ }^{66}$ Law Society of New South Wales, A Practical Guide for Solicitors: When a Client's Mental Capacity is in Doubt (Law Society of New South Wales, 2016). See:

<https://www.lawsociety.com.au/cs/groups/public/documents/internetcontent/1191977.pdf>. Queensland Law Society, Queensland Handbook for Practitioners on Legal Capacity (Queensland Law Society, 2014). See $<$ https://www.qls.com.au/files/4422042a-7f34-404f-8df5-

a49d00e5f89a/Queensland_Handbook_for_Practitioners_on_Legal_Capacity.pdf $>$. Law Institute of Victoria, Client Capacity Guidelines and Toolkit - Taking Instructions When a Client's Capacity is in Doubt (October 2016) $<$ https://www.liv.asn.au/PDF/For-Lawyers/Submissions-and-LIV-Projects/2054_LPP_CapacityGuidelines_FINAL_WEB> ${ }^{67}$ Warning signs include: problems with memory and recalling information; communication difficulties; limited ability to interact; difficulty doing simple calculations; letting family members or others speak for them; being in hospital or aged care facility. Ibid.

${ }^{68}$ See eg ibid: NSW Guide, (at 4): 'People whose cognitive capacity is impaired may be vulnerable to exploitation by others and may not be able to protect their own legal interests. Solicitors have ethical duties to the court, their clients and to the administration of justice to ensure that the interests of their clients are promoted and protected at all times.' The Victoria Guidelines remind lawyers (at p 4): 'Be wary of potential undue influence.' The Queensland Guidelines state that lawyers must 'be alive to any undue influence the third party exercises over the client (or any advantages or benefits they seek to achieve)' (at 32) and advises lawyers to contact the Public Trustee if they have concerns about abuse of a client (at 82).
} 
reluctance to refer clients to medical practitioners for comprehensive capacity assessments, and providing inadequate contextual information when an external assessment is requested. ${ }^{69}$ The New South Wales inquiry into elder abuse and the Office of the Legal Services Commissioner have both recognised a need for capacity assessment training targeted at lawyers. ${ }^{70}$

A growing body of research identifies financial decision-making capacity as an area of functioning likely to be affected in the early stages of cognitive decline, even prior to a diagnosis of dementiarelated disease. ${ }^{71}$ In addition to following general capacity assessment guidelines issued by legal professional bodies, lawyers may consider the use of screening tools designed specifically to identify impairments in clients' financial comprehension, for example, in ascertaining a client's capacity to instruct on a financial transaction.

The Lichtenberg Financial Decision Screening Scale has been developed for use by a range of professionals including lawyers, health and social care providers, and financial planners. It is designed to assess a client's financial decision-making capacity specific to a real decision or transaction, rather than using hypothetical scenarios. ${ }^{72}$ It is easily administered as a ten-item scale using multiple-choice

\footnotetext{
${ }^{69}$ See eg Kelly J Purser and Tuly Rosenfeld, 'Evaluation of Legal Capacity by Doctors and Lawyers: The Need for Collaborative Assessment' (2014) 201(8) Medical Journal of Australia 483. See also Lise Barry, Submission No. 21 to NSW Elder Abuse Inquiry (n 3), 15 November 2015. See

$<$ https://www.parliament.nsw.gov.au/committees/inquiries/Pages/inquiry-submission-details.aspx?pk=02053753>.

${ }^{70}$ NSW Elder Abuse Inquiry (n 3), 117-118; Office of the Legal Services Commission (n 10).

${ }^{71}$ Michael S Finke, John S Howe and Sandra J Huston, 'Old Age and the Decline in Financial Literacy' (2017) 63(1) Management Science 213; Peter A Lichtenberg, 'Financial Exploitation, Financial Capacity, and Alzheimer's Disease' (2016) 71(4) American Psychologist 312; Mark S Lachs and S Duke Han, 'Age-Associated Financial Vulnerability: An Emerging Public Health Issue’ (2015) 163(11) Annals of Internal Medicine 877; RN Spreng, J Karlawish and DC Marson, 'Cognitive, Social, and Neural Determinants of Diminished Decision-Making and Financial Exploitation Risk in Aging and Dementia: A Review and New Model' (2016) 28(4-5) Journal of Elder Abuse and Neglect 320.

${ }^{72}$ Peter A Lichtenberg and others, 'Reliability and Validity of the Lichtenberg Financial Decision Screening Scale' (2017) 1(1) Innovation in Aging; Peter A Lichtenberg and others 'The Lichtenberg Financial Decision Screening Scale (LFDSS): A New Tool for Assessing Financial Decision Making and Preventing Financial Exploitation' (2016) 28(3) Journal of Elder Abuse and Neglect 15. See also Peter A Lichtenberg and others 'A Person-Centered Approach to Financial Capacity Assessment: Preliminary Development of a New Rating Scale’ (2015) 38(1) Clinical Gerontologist 65. Other financial capacity assessment tools use hypothetical scenarios: see eg MM Kershaw and LS Webber, 'Assessment of Financial Competence' (2008) 15 Psychiatry, Psychology and Law 40 and DC Marson and others, 'Clinical Interview Assessment of Financial Capacity in Older Adults with Mild Cognitive Impairment and Alzheimer's Disease (2009) 57(5) Journal of the American Geriatrics Society 806.
} 
questions, and can be completed in approximately five to seven minutes. ${ }^{73}$ The older person is asked to identify the financial decision they are considering (or have made), such as giving a gift or loan or making a major purchase or sale. They are then asked to specify details such as the purpose of the decision, how it will affect them, who will benefit most from the decision, and how much risk is involved for the financial situation. The screening tool can also be used for investigation of a potential abuse situation to identify the older person's understanding of a financial decision or transaction they have already made.

It is also important for lawyers to be aware of additional ethical issues that arise when assessing capacity in a situation of suspected elder abuse, particularly to provide a private and safe environment.

O’Connor, Hall and Donnelly outline several key questions: "Can some level of safety be ensured? Is there space for the person to tell his or her story in a safe, secure atmosphere? How will the person, competent or not, be protected following the assessment? How can the assessment of capacity integrate a means for considering potential levels of intimidation, prompting, and/or 'undue influence'?"74 The stress of being in an abusive situation may affect the client's cognitive abilities and providing the client with information and supports to address abuse or exploitation, for example in a family relationship, can help to enhance their capacity to make choices on other matters.

\section{Screening of suitability to be appointed as a decision-maker}

The law enables people to plan for future incapacity by appointing individuals who will have authority to make financial, health and other decisions in circumstances where the appointor is unable to do so. A common finding across all recent Australian inquiries is that substitute decision-making appointments

\footnotetext{
${ }^{73}$ The screening tool and instructions on use are available online at www.olderadultnest.egg.com. New users must register to access the tool but access is free of charge.

${ }^{74}$ O’Connor, Hall and Donnelly, 'Assessing Capacity Within a Context of Abuse or Neglect' (n 33), 162.
} 
are used to perpetrate abuse, particularly in the case of people with financial power of attorney carrying out transactions for their own gain. ${ }^{75}$

Some jurisdictions now recognise a supportive attorney role, whereby a person with a disability can legally appoint one or more supporters, such as a family member or friend, to assist them with decisionmaking. ${ }^{76}$ The person making the appointment must have the capacity to do so, but may then call on the supporter to assist during periods of reduced capacity, which may be the case for an older person with dementia who experiences fluctuations in their cognitive abilities. In Victoria, Australia, a supportive attorney may, for example, accompany the older person to appointments with legal, health and financial professionals, access the older adult's personal information (such as health and banking records), and help the older person to understand and weigh their options. The supporter does not have legal authority to make the decision in place of the older person, but an unscrupulous individual could exploit the role to influence a decision that suits their interests over that of the older adult.

Lawyers can play an important preventive role by educating clients about ways to protect themselves from abuse, especially when appointing decision-makers and supporters. Courts have found lawyers in breach of their ethical duties to clients where they have not clearly explained the authority of these appointees and ensured the client had an adequate understanding of the implications of giving formal powers to a third party. ${ }^{77}$ Lawyers and others who draft and execute enduring documents should, according to the Law Council of Australia, be able to advise the person making the document of the

\footnotetext{
${ }^{75}$ ALRC Elder Abuse Report (n 8), see esp Chapter 5, Enduring Appointments <https://www.alrc.gov.au/publications/5enduring-appointments>.

${ }^{76}$ See eg Victoria, Australia: Powers of Attorney Act 2014; Alberta, Canada: Adult Guardianship and Trusteeship Act 2008; Ireland: Assisted Decision-Making (Capacity) Act 2015; Texas USA: Supported Decision-Making Agreement Act. 77 Szozda v Szozda [2010] NSWSC 804. The client in this case was a 99-year-old woman with dementia. The Court stated that it is not sufficient for a solicitor to be satisfied that a client understands a power of attorney appointment by a merely asking 'do you understand' and being told 'yes I understand.' In this case, the solicitors did not describe to the client 'any particular things that the attorney could do... nor did either probe Mrs Szozda by, for example, asking her to repeat what had been said to her or putting questions about aspects of her property or affairs which might have formed a basis for specific questions or comments designed to ensure that an informed understanding had been received or was held.' [119]
} 
'attributes most desired in an attorney. ${ }^{78}$ These attributes are typically expressed at a general level, for example: 'Is that person someone who is trustworthy and sufficiently responsible and wise to deal prudently with my affairs and to judge when to seek assistance and advice? The decision is one in which considerations of surrender of personal independence and considerations of trust and confidence play an overwhelmingly predominant role. ${ }^{79}$ The development of a specific set of screening questions could help improve practices and identify in a more systematic way characteristics or behaviours that may raise questions about the suitability of the proposed appointee. While there is no single abuser profile, some common characteristics have been identified for people who commit different types of abusive acts. ${ }^{80}$ For example, characteristics such as substance use problems, limited social networks, and financial dependence on the older person have been identified as risk factors for engaging in abusive behaviours. $^{81}$

The author is unaware of a published tool that has been designed specifically to identify whether a prospective appointee may abuse that role and this is an important area for further research with the legal profession and older client groups. ${ }^{82}$ Other tools exist to determine the possibility that a caregiver for an older person may commit abuse. For example, the Caregiver Abuse Screen for the Elderly $(\mathrm{CASE})^{83}$ is an eight-question tool is designed to be completed by the caregiver and uses nonconfrontational wording to encourage honest responses. It asks questions such as: "Do you sometimes

\footnotetext{
${ }^{78}$ ALRC Elder Abuse Report (n 8), 170.

${ }^{79}$ Szozda v Szozda [2010] NSWSC 804, [34]. See also New South Wales Trustee and Guardianship website, $<$ http://www.tag.nsw.gov.au/attorney-faqs.html>.

${ }^{80}$ Shelly L Jackson and Thomas L Hafemeister, 'How Case Characteristics Differ Across Four Types of Elder Maltreatment: Implications for Tailoring Interventions to Increase Victim Safety’ (2014) 33(8) Journal of Applied Gerontology 982; Marguerite DeLiema and others, 'Using Latent Class Analysis to Identify Profiles of Elder Abuse Perpetrators' (2017) Journal of Gerontology B: Psychological Sciences and Social Sciences.

${ }^{81}$ Ibid; Travis Labrum and Phyllis L Solomon, 'Elder Mistreatment Perpetrators with Substance Abuse and/or Mental Health Conditions: Results from the National Elder Mistreatment Study' (2017) Psychiatry Quarterly.

${ }^{82}$ For example, in a submission to the NSW Elder Abuse Inquiry, the Queensland Law Society recommended further research into 'risk reduction strategies ... [such as] structured decision-making tools to guide decisions about the appointment of attorneys.' Queensland Law Society, Submission No. 159 (29 August 2016) $<$ https://www.alrc.gov.au/sites/default/files/subs/159._queensland_law_society_qls.pdf $>$.

${ }^{83}$ M Reis and D Nahmiash, 'Validation of the Caregiver Abuse Screen (CASE)' (1995) 14 Canadian Journal on Aging 45.
} 
feel that you are forced to be rough with [the older person]?" "Do you sometimes feel that you can't do what is really necessary or what should be done for [the older person]?” The CASE is considered a valid and reliable tool to identify the potential for abusive behaviour among family caregivers, including those caring for a relative with dementia. ${ }^{84}$ Other screening tools are available to identify abusive behaviours; for example, Cooper and colleagues used the Modified Conflict Tactics Scale to screen caregivers for physically and emotionally abusive behaviour towards older people with dementia. ${ }^{85}$ This questionnaire asks how often in the past three months the carer had engaged in any one of ten physically and emotionally abusive behaviours, including: screaming or yelling at the person; threatening to move the person to an aged care facility; threatening to stop providing care; and handling the person in a rough manner. The authors concluded that caregivers are willing to complete the questionnaire honestly and that it could be incorporated into routine practice to detect situations of clinically concerning abuse.

These types of tools may have limited applicability to the legal setting, however, since the older person is the lawyer's client and the lawyer may not interact directly with the family member, caregiver, or other person who may be appointed into a substitute or supported decision-making role. Of more relevance for lawyers would be screening questions they could use with their client to discuss the suitability of another person to take on the responsibilities as a financial power of attorney or a health or personal decision-maker or supporter. This approach is preventive, supports older clients to reflect on their wishes, preferences and risk tolerance, and to make choices that can decrease their vulnerability. The New South Wales Inquiry underscored the importance of 'strength based initiatives which empower older persons to better protect themselves from risks of abuse as they age. ${ }^{, 86}$ A preventive screening

\footnotetext{
${ }^{84} \mathrm{MG}$ 'Validation of the Italian Version of the Caregiver Abuse Screen among Family Caregivers of Older People with Alzheimer's Disease' (2017) Biomed Research International, doi: 10.1155/2017/3458372; Pérez-Rojo G, Nuevo R, Sancho M, Penhale B, Validity and reliability of the Spanish version of Caregiver Abuse Screen (CASE) (2015) 37(1) Research on Aging 63.

${ }^{85}$ Claudia Cooper and others, 'The Sensitivity and Specificity of the Modified Conflict Tactics Scale for Detecting Clinically Significant Elder Abuse' (2009) 21(4) International Psychogeriatrics 774. See Scott R Beach and others, 'Risk Factors for Potentially Harmful Informal Caregiver Behavior' (2005) 53 Journal of the American Geriatrics Society 255 for the development of the scale.

${ }^{86}$ NSW Elder Abuse Inquiry (n 3), iv.
} 
approach has advantages over other measures that may deter appointed decision-makers from abusing their authority, such as requiring them to sign a declaration promising to behave or enacting and enforcing statutory penalties for those who misbehave ${ }^{87}$ It is possible that such provisions could have a deterrent effect but, if not, penalties are reactive and imposed after an older person has been subjected to abuse. Therefore, they will arguably be of limited utility in preventing the mistreatment of older people.

\section{Implementing screening in practice}

Screening should be approached as enabling a process of communication that fosters a therapeutic relationship between the older client and the lawyer. The focus should be on person-centred strategies ${ }^{88}$ that enhance the older person's strengths and enable decision-making based on their values and preferences. ${ }^{89}$ Screening can be accomplished in different ways. Clients could be asked to complete a brief screening questionnaire while waiting for an appointment and the answers can be reviewed during the consultation. ${ }^{90}$ However, most screening tools are designed to be completed in verbal conversation between the professional and the client, which allows for privacy, observations of body language, and immediate responses to any queries or concerns raised by the client.

The physical meeting space and communication style should invite the client to feel safe and supported. ${ }^{91}$ Lawyers must be aware of, and neutralise, power imbalances in their interactions with older

\footnotetext{
${ }^{87}$ For discussion and examples of such measures, see ALRC Elder Abuse Report (n 8), Chapter 5, Enduring Appointments $<$ https://www.alrc.gov.au/publications/5-enduring-appointments $>$.

${ }^{88}$ John Chesterman, 'Taking Control: Putting Older People at the Centre of Elder Abuse Response Strategies' (2016) 69(1) Australian Social Work 115.

${ }^{89} \mathrm{~S}$ Fazio, 'The Individual is the Core - and Key - to Person-Centered Care' (2013) 37(3) Generations 16.

${ }^{90}$ This approach was used in the study where the HS-EAST was used in a free legal advice clinic: Strasser and others, 'Screening for Elder Mistreatment Among Older Adults Seeking Legal Assistance Service' (n 28). For discussion of the selfadministration approach, see eg. Mark J Yaffe, Deborah Weiss and Maxine Lithwick, 'Seniors' Self-Administration of the Elder Abuse Suspicion Index (EASI): A Feasibility Study' (2012) 24(4) Journal of Elder Abuse and Neglect 277.

${ }^{91}$ Practical examples include: round table seating instead of having a desk between the lawyer and client; ensuring the client is physically comfortable, particularly if they have mobility limitations; using plain language and explaining any technical terms; addressing any sensory impairments (eg, hearing, sight); confirming the client hears and understands questions; printing large font documents; and giving the client time to answer fully. See Rebecca C Morgan, 'The Practical Aspects of Practicing Elder Law: Creating an Elder-Friendly Office’ (2004) 38(2) Family Law Quarterly 269.
} 
clients, particularly when broaching sensitive issues related to potential abuse and decision-making capacity. As an authority figure, the lawyer 'may inadvertently position the person being assessed in a one-down position, effectively disempowering that person and limiting his or her responses.' ${ }^{92}$ Lawyers must be careful to avoid stigmatising language that may shut down rather than open up conversations with clients. For example, making negative comments about a spouse or adult child who is engaging in potentially abusive behaviour may imply criticism of the client's family relationships. Moreover, it is important for lawyers to understand that 'there is a spectrum of behaviors that older people may be reluctant to describe as elder abuse yet require assistance in managing. ${ }^{, 93}$

Training on effective interviewing and counseling techniques would be particularly beneficial for junior practitioners new to working with older clients, as their legal education and practical training may not have equipped them with the knowledge and skills relevant to capacity assessment and screening for elder abuse. ${ }^{94}$ Experienced practitioners may be more attuned to warning signs and there has been 'some conjecture concerning whether or not this expertise could be taught or is only acquired through experience. ${ }^{95}$ Online educational interventions have been shown to help novice health and social care practitioners improve their skills in recognising signs of abuse ${ }^{96}$ and legal education and professional organisations can adapt such strategies for training to support junior lawyers in meeting their ethical obligations when working with older clients. Some useful tools already exist, including training aids and educational resources on elder financial abuse. ${ }^{97}$

\footnotetext{
92 O’Connor, Hall and Donnelly, 'Assessing Capacity Within a Context of Abuse or Neglect' (n 33 ) 164.

${ }^{93}$ Naughton and others, 'The Relationship Between Older People's Awareness of the Term Elder Abuse and Actual Experiences of Elder Abuse' (n 20) 1263.

${ }^{94}$ For discussion of an experiential learning initiative to enhance law students' skills in these areas, see eg. Nola M Ries, Briony Johnston and Shaun McCarthy, 'Legal Education and the Ageing Population: Building Student Knowledge and Skills Through Practical Experiences in Collaboration with Community Organisations' (2016) 37(2) Adelaide Law Review 495.

${ }_{95}$ Pleasance and others, Reshaping Legal Assistance Services (n 51), 154

${ }^{96}$ P Harries and others, 'Educating Novice Practitioners to Detect Elder Financial Abuse: A Randomised Controlled Trial' (2014) 14 BMC Medical Education 21.

${ }^{97}$ A research team at Brunel University (London) have undertaken extensive research work to develop materials that are available for use: see $<$ http://elderfinancialabuse.co.uk/index.html $>$.
} 


\section{Assisting clients at risk for or experiencing abuse}

Professionals who work with older clients report that barriers to screening for elder abuse include uncertainty over what to do when situations of concern are identified and fear that triggering protective interventions could alienate the client. ${ }^{98}$ Three core features have been identified in healthcare literature as best practices when working with a client in a situation of elder abuse: (1) tailoring interventions to the older person; (2) using multiple strategies, such as education on their rights and referrals to services; and (3) ensuring actions are acceptable to the older person. ${ }^{99}$ These general steps are equally applicable to lawyers and can be applied in conjunction with professional conduct and ethics rules when advising clients on options in abuse situations.

Lawyers have duties to act in a client's best interests, to provide clear and timely advice, and to maintain confidentiality. ${ }^{100}$ Within this ethical context, the advice and supports offered to older clients and actions taken will vary depending on a range of factors including: the severity and immediacy of potential or actual harm to the older client; the extent to which possible actions to address the abuse are within the lawyer's scope of practice and expertise; and the types of supports available in the community, which may range from specialist elder abuse programs to preventive resources for older adults, such as social visiting and financial literacy programs. As discussed below, responses will also depend on legislative requirements for mandatory reporting of elder abuse that may apply in the lawyer's jurisdiction of practice.

\footnotetext{
${ }^{98}$ PR Baker and others (n 45).

${ }^{99}$ Sandra P Hirst and others, 'Best-Practice Guidelines on the Prevention of Abuse and Neglect of Older Adults' (2016) 35(2) Canadian Journal on Aging 242, 254 (internal citations omitted). The authors' recommendations are based on a systematic review of literature dealing with Canadian healthcare settings, however, the three key steps are helpful for professionals in other disciplines and jurisdictions.

${ }^{100}$ See eg, Law Council of Australia, Australian Solicitors Conduct Rules, Rules 4 (best interests), Rule 7 (advice), and Rule 9 (confidentiality) (August 2015). See $<$ https://www.lawcouncil.asn.au/files/web-pdf/Aus_Solicitors_Conduct_Rules.pdf $>$ [Solicitors Conduct Rules].
} 
In some cases, the issues revealed through elder abuse screening may be well within the lawyer's scope and amenable to legal preventive strategies or remedies. For example, the lawyer may learn that the client's adult child has been pressuring them to sign documents to transfer the family home with a promise of caring for the parent at home as they age. A properly drafted family agreement can protect the client's interests if they wish to exchange their assets for care commitments. ${ }^{101}$ In situations where ongoing abuse is identified, there may be immediate risks to the client's health and safety, such as physical violence or denial of vital medication, that raise a need for input and supports that extend beyond the lawyer's scope and expertise. Referrals or reports to other agencies and practitioners may be important options to consider but may raise ethical dilemmas in relation to duties of confidentiality and loyalty to the client.

\section{Confidentiality duties}

Lawyers may be concerned that their confidentiality duties preclude contact with services to assist in situations of elder abuse. ${ }^{102}$ In Australia, the Solicitors Conduct Rules permit a lawyer to disclose confidential client information in several circumstances, as discussed below. ${ }^{103}$ Some similar exceptions to confidentiality exist in conduct rules elsewhere. ${ }^{104}$

Typically, a lawyer may disclose confidential information with the client's consent. ${ }^{105}$ For example, the lawyer may initiate a call to elder abuse services with the client present and, so far as the client agrees,

\footnotetext{
${ }^{101}$ For discussion and resources, see eg Seniors Rights Victoria, Assets for Care: A Guide for Lawyers to Assist Older Clients at Risk of Financial Abuse (2012), https://assetsforcare.seniorsrights.org.au/assetsforcare/wpcontent/uploads/2014/10/Assets-for-Care.pdf.

${ }^{102}$ ALRC Elder Abuse Report, (n 8), acknowledged confidentiality concerns, citing, for example, a submission by the Institute of Legal Executives which suggested 'that the professional rules for legal practitioners in various jurisdictions might need to be reviewed to ensure lawyers can report abuse without facing professional sanctions.' Submission No. 320, [14.182] $<$ https://www.alrc.gov.au/inquiries/elder-abuse/submissions $>$. Note that this does not refer to reporting under a mandatory reporting law, which the ALRC decided not to recommend. The report discusses instead the development of professional guidelines to support the voluntary reporting of serious abuse situations, ideally with client agreement.

${ }^{103}$ Solicitors Conduct Rules (n 100), Rule 9 - Confidentiality.

${ }^{104}$ For examples of confidentiality exceptions in the American context, see M Sholian, 'An Ethical Dilemma: Attorneys' Duties Not to Reveal Elder Abuse in Washington State' (2015) 90 Washington Law Review 1471.

${ }^{105}$ Solicitors Conduct Rules, (n100), [9.2.1].
} 
participate in a conversation that helps the client express their concerns and seek information on supports they could access. Seeking client consent to such contact with other service providers respects the rights of older adults to make their own choices. ${ }^{106}$ As the Australian Law Reform Commission stated in its elder abuse inquiry: 'Older people, like most adults, prize their freedom and independence, and do not wish to be treated like children or sheltered from all risk. The autonomy of older people should not be afforded less respect than the autonomy of others. ${ }^{, 107}$

The Commission qualifies this general principle, however, stating that 'in limited cases, where there is particularly serious abuse of vulnerable people, protection should be given additional weight.' ${ }^{108}$ The values of respect for autonomy and protection from harm do not necessarily conflict, ${ }^{109}$ but lawyers may face ethical dilemmas in balancing these interests when an older client does not consent to contact with service providers outside the lawyer-client relationship. It is not uncommon for older adults in abusive situations to reject services, ${ }^{110}$ however, according to a 2016 report on elder abuse interventions in one Australian state, older people who received help to deal with abusive situations urge service providers to provide earlier referrals and supports when abuse or risk factors are identified. ${ }^{111}$ Sandusky advises that 'a lawyer does not merely give up after his or her client refuses ... Lawyers need to take the time to understand the rationales behind their client's decisions and present escape options that comport with

\footnotetext{
106 See eg New South Wales Government, Preventing and Responding to Abuse of Older People: NSW Interagency Policy. (2015) <http://www.elderabusehelpline.com.au/uploads/pdf/FACS-NSW-Interagency-Policy-updated-November-2015.pdf $>$ [NSW Interagency Policy]. 
the client's overall goals and values.' ${ }^{112}$ Elder law literature recommends the use of a 'gradual counseling' process to help elicit the client's concerns, values, motivations and goals, as well as the thinking that informs their choices. ${ }^{113}$ It is vital for lawyers to explore the client's rationale for rejecting assistance and provide information to address fears or correct misapprehensions. Where a client decides they do not want to pursue legal steps or request assistance from other agencies, lawyers should ensure the client has information on community supports they may access in the future should they wish to do so.

In more extreme situations of elder abuse, professional conduct rules may permit disclosure of confidential information to protect the client from serious criminal acts or other significant harms. In Australia, a lawyer is permitted to disclose client information where doing so would prevent the 'probable commission of a serious criminal offence" ${ }^{\text {'14 }}$ or 'imminent serious physical harm to the client. ${ }^{115}$ A serious criminal offence encompasses offences such as common assault, including threats to harm where no physical contact is made, assault occasioning actual bodily harm, including bruises, scratches and psychological trauma, sexual and indecent assaults, and most frauds, including obtaining property or a financial advantage by deceptive or dishonest means. ${ }^{116}$ Prior to any decision to disclose information without the client's consent, the lawyer should explain how various forms of abuse may constitute criminal offences, advise on immediate legal measures that can protect the older client (such as seeking an order restraining an abusive person from having contact with the client), and discuss legal processes and potential outcomes. The client can then make an informed choice about filing a complaint

\footnotetext{
${ }^{112}$ Sarah S Sandusky, 'The Lawyer's Role in Combating the Hidden Crime of Elder Abuse' (2004) 2 Elder Law Journal 459, 487.

${ }^{113}$ American scholar, Linda Smith, proposed the gradual counselling approach to explore an older client's thinking and choices where capacity is in question: Linda F Smith, 'Representing the Elderly Client and Addressing the Question of Competence' (1988) 14 Journal of Contemporary Law 61. The approach has since been applied to interviewing and counseling a client in the context of elder abuse: see Sandusky, ibid, who suggests the gradual counselling process may encourage the client to consent to disclosure of information to external services, however, the impact of lawyers' counselling strategies on client decision-making is a matter that requires empirical investigation. In Australia, the New South Wales Law Society endorses the gradual counselling approach in its solicitors' guide on client capacity issues (n 66), 61.

${ }^{114}$ Solicitors Conduct Rules (n 100), [9.2.4].

${ }^{115}$ Ibid, [9.2.5].

${ }^{116}$ Ibid, Glossary of Terms.
} 
with authorities.

In Australia, a lawyer may also share client information in confidence in order to seek advice on their legal or ethical duties, ${ }^{117}$ for example, by consulting an ethics advisor employed by their legal regulatory body. ${ }^{118}$ Such input can help to clarify professional responsibilities in difficult situations where a client at risk of or experiencing serious harm declines to take protective steps.

Client information may also be disclosed where compelled by law, ${ }^{119}$ however in Australia, lawyers and other professionals do not have a legal duty to report cases of suspected elder abuse to authorities. ${ }^{120}$ Lawyers elsewhere must be aware of elder abuse reporting laws in their jurisdiction of practice, to whom and in what circumstances they apply, and any provisions related to information acquired in the context of a confidential professional relationship. ${ }^{121}$ The arguments for and against mandatory reporting and specialist elder abuse laws have been canvassed elsewhere. ${ }^{122}$ In general, critics contend that systems of compulsory reporting are disempowering, disrespect older people's privacy and selfdetermination, and cannot be justified by analogy to child abuse reporting. ${ }^{123}$ Advocates cite the adverse

\footnotetext{
${ }^{117}$ Ibid, [9.2.3].

${ }^{118}$ With growing awareness of the prevalence of elder abuse, more professional resources are being developed for lawyers to offer guidance on ethical responsibilities and legal options for different forms of abuse. See eg, Amerian Bar Association, Commission on Aging, Elder Abuse (2018) < https://www.americanbar.org/groups/law_aging/resources/elder_abuse.html>. In England, a recent practice-focused book focuses on financial abuse, covering various actions that can be taken when abuse is discovered, including investigations and recovery of assets: Ann Stanyer, Financial Abuse of Older Clients: Law, Practice and Prevention (Bloomsbury Professional, 2017).

${ }^{119}$ Solicitors Conduct Rules (n 100), [9.2.2].

${ }^{120}$ NSW Elder Abuse Inquiry, (n 3), 20. Note, however, that the federal Aged Care Act 1997 requires approved providers of residential aged care to report to police and to the Department of Health incidents involving sexual and serious physical assaults: <https://agedcare.health.gov.au/ensuring-quality/aged-care-quality-and-compliance/guide-for-reporting-reportableassaults $>$.

${ }^{121}$ For a review of reporting laws in the United States and implications for lawyers, see M Sholian, 'An Ethical Dilemma: Attorneys' Duties Not to Reveal Elder Abuse in Washington State' (2015) 90 Washington Law Review 1471. Sholian also discusses ethics opinions and guidelines prepared by some State Bar Association to clarify ambiguities in the interpretation of elder abuse reporting laws and legal professional conduct rules. See also summary of laws prepared by the National Adult Protective Services Association, 2013 Nationwide Survey of Mandatory Reporting Requirements for Elderly and/or Vulnerable Persons (updated 2015) <http://www.napsa-now.org/wp-content/uploads/2016/05/Mandatory-Reporting-ChartUpdated-December-2015-FINAL.pdf $>$.

${ }^{122}$ ALRC Report (n 8), Chapter 14, Safeguarding Adults at Risk; L Montgomery and others (n 109).

${ }^{123}$ Brank and colleagues argue: 'Relying on mandatory reporting of older adults is fundamentally different from mandatory reporting for children because we should be considering older adults' privacy rights and autonomy rather than only
} 
morbidity and mortality impacts of elder abuse and the imperative of minimising preventable harms, especially for people who experience the intersecting vulnerabilities of age, ill health and social exclusion. ${ }^{124}$

In Australia, legal organisations that serve older adults have stressed:

[a]ny legal response [to elder abuse] must recognise the right of the older person to decide not to pursue legal remedies and accommodate those wishes. Any interventions that unnecessarily impose on an older person's right to autonomy and self-determination and fail to afford them the "dignity of risk" may create adverse consequences." 125

Ultimately, the position advocated in this article is that the aim of asking screening questions should be to open a conversation about issues that are too often ignored, and to support - but not coerce - older clients to access appropriate legal, health and other community services.

\section{Recommendations for Further Research}

To support evidence-based practices in elder abuse detection and response, well-designed research is needed to implement and evaluate the screening tools discussed in this article. ${ }^{126}$ In general, there is a lack of rigorous research evidence on what interventions work to identify, manage and prevent elder abuse. ${ }^{127}$ In a recent systematic review, Ayalon and colleagues call for more research to investigate

considering the state's interest in protecting older adults.' Eve M Brank, Lindsey E Wylie and Joseph A Hamm, 'Potential for Self-Reporting of Older Adult Maltreatment: An Empirical Examination" (2011-2012) 19 Elder Law Journal $351,361$.

${ }^{124}$ Lisa M Gibbs and Laura Mosqueda, 'The Importance of Reporting Mistreatment of the Elderly' (2007) 75(5) American Family Physician 628.

125 Justice Connect, Submission No. 182 (September 2016) to ALRC Elder Abuse Inquiry (n 8), see < https://www.alrc.gov.au/sites/default/files/subs/182. justice_connect.pdf $>$.

${ }^{126}$ Mark J Yaffe and others, 'Development and Validation of a Tool to Improve Physician Identification of Elder Abuse' (n 59), 285; Xin Qi Dong, 'Elder Abuse: Systematic Review and Implications for Practise' (2015) 63(6) Journal of the American Geriatrics Society 1233; Xin Qi Dong, Ruijia Chen and Melissa A. Simon, 'Elder Abuse And Dementia: A Review Of The Research And Health Policy’ (2014) 33(4) Health Affairs 647; Tony Rosen, Stephen Hargarten, Neal E Flomenbaum, Timothy F Platts-Mills, 'Identifying Elder Abuse in the Emergency Department: Toward a Multidisciplinary Team-Based Approach' (2016) 68(3) Annals of Emergency Medicine September 8380; MJ Schofield and GD Mishra, 'Validity of SelfReport Screening Scale for Elder Abuse' (n 63), 111.

${ }^{127}$ PR Baker and others ( $\mathrm{n} 45$ ). The authors conclude: 'There is inadequate trustworthy evidence to assess the effects of elder abuse interventions on occurrence or recurrence of abuse...' 
interventions targeted at improving the knowledge and skills of professionals who have responsibilities to identify and act on elder abuse. ${ }^{128}$ Lawyers are a key professional group to include in such work.

At the time of writing, the author is co-leading a pilot project in New South Wales, Australia that brings together legal and health service providers who will take part in training on identifying and responding to elder abuse. They will then trial the use of a brief screening tool with their older clients and report on their experiences. A key aim of the pilot study is to investigate service providers' experiences in dealing with elder abuse situations and their views on incorporating a screening process into their everyday practice. The findings will be published and used to inform further intervention studies to build an evidence base in this area.

Process and outcome data are both important in research that evaluates elder abuse screening. In regard to process, a key issue is how to incorporate screening into practice in ways that are feasible and acceptable to clients, lawyers and other service providers. In regard to outcomes, existing elder abuse screening tools have not been evaluated to determine their impacts in reducing the occurrence of abusive behaviours and improving the health and well-being of older people. ${ }^{129}$ Longer term studies are needed to follow older clients over time to determine if screening for abuse in fact leads to earlier interventions and supports that mitigate the impacts of abuse and prevent future abuse from occurring. Such research can also be linked with work to investigate older clients' capability in relation to legal problem solving and uptake of services. ${ }^{130}$

\footnotetext{
${ }^{128}$ Liat Ayalon and others 'A Systematic Review and Meta-Analysis of Interventions Designed to Prevent or Stop Elder Maltreatment' (2016) 45 Age and Ageing 216.

${ }^{129}$ Gallione and others, 'Screening Tools for Identification of Elder Abuse' (n 5).

${ }^{130}$ Pleasance and others, Reshaping Legal Assistance, (n 51), p 158. The authors state: 'Further research is needed to determine how feasible it is to incorporate legal capability testing and screening, and whether it can be sufficiently streamlined to have utility.'
} 
Research studies also need to involve older people and elicit their perspectives and experiences.

Surprisingly, no published studies report on the acceptability of elder abuse screening to older people. ${ }^{131}$ Harbison and colleagues point out that 'older people's voices about "elder abuse and neglect" are missing, and the abilities, needs and wishes of older people perceived as victims are subsumed under professional ... expertise.' ${ }^{132}$ These knowledge gaps must be remedied by giving a voice to older people. Researchers who seek to involve older people in studies report challenges in obtaining ethics approval, especially if participants are considered vulnerable due to age and potential cognitive impairment and the study investigates a sensitive topic such as abuse within family and caregiving relationships. ${ }^{133}$ Carefully designed studies that provide appropriate protections for participants are needed and the recommendations of researchers with expertise in gerontology fields can guide future work. ${ }^{134}$

Elder abuse is a complex problem and its identification, management and prevention requires practitioners across multiple sectors to work together. ${ }^{135}$ Partnerships involving legal, health and social care professionals provide useful models for collaborative practice and evaluation data from such initiatives will add to the much-needed evidence base for understanding what works to improve detection and action. ${ }^{136}$

\footnotetext{
${ }^{131}$ Gallione and others, 'Screening Tools for Identification of Elder Abuse' (n 5).

${ }^{132}$ Harbison and others, Contesting Elder Abuse, (n 15) 6.

${ }^{133}$ Nola M Ries, Katie Thompson and Michael Lowe, 'Including People with Dementia in Research: An Analysis of Australian Ethical and Legal Rules and Recommendations for Reform' (2017) 14(3) Journal of Bioethical Inquiry 359; Nancy Pachana and others, 'Can We Do Better? Researchers' Experiences with Ethical Review Boards on Projects with Later Life as a Focus' (2015) 43(3) Journal of Alzheimers Disease 701.

${ }^{134}$ See eg, K Murphy and others, 'Articulating the Strategies for Maximising the Inclusion of People with Dementia in Qualitative Research Studies’ (2015) 14(6) Dementia 800. The authors propose a strategy to maximise ways for people living with dementia to tell their stories to researchers and this same approach can guide work with older adults at risk for or experiencing abuse.

${ }^{135}$ The author agrees with Strasser and others: 'More collaboration among professionals from diverse disciplines who play a role in EM [elder mistreatment] identification and resolution is needed. ... Traditionally the responsibility for recognizing, identifying, and responding to EM has been assumed primarily by healthcare professionals. ... However, through effective screening, EM may be detected before it escalates...' 'Screening for Elder Mistreatment Among Older Adults Seeking Legal Assistance Service (n 28), 314.

${ }^{136}$ See eg in Australia: Justice Connect, Working Together - A Health Justice Partnership to Address Elder Abuse, First Year Report (March 2016), <https://www.justiceconnect.org.au/sites/default/files/HJP_first\%20year\%20report_web.pdf>;
} 


\section{Conclusion}

In their professional practice, lawyers will come into contact with older clients who are at risk for or experiencing abuse and exploitation. These situations may be more or less obvious and lawyers need to be equipped with the knowledge and skills to ask and act in ways that ensure they provide ethically responsible services to their older clients. Prudent lawyers make enquiries or, put another way, lawyers who 'get an inkling ... that the client may be a victim of elder abuse ... must continue, gently but directly, to ask questions of the older adult in order to better understand the situation and to be able to advise the client appropriately.' ${ }^{137}$ Moving beyond this general advice, this article has proposed screening strategies in three interrelated areas and identified specific screening tools that can be adapted for use by legal professionals. It has focused on brief screening questionnaires that are quick to administer and elicit relevant information in a standardised format. Such tools reduce reliance on individual practitioners' gut feelings and can improve their confidence in broaching sensitive topics with clients. ${ }^{138}$ Lawyers who do a better job of identifying clients at risk for abuse can provide preventive advice that enables clients to take steps to protect themselves. When screening reveals that a client is currently being harmed or has been the victim of past abuse, appropriate follow-up advice and steps can be taken to assist the client in achieving outcomes that advance their interests.

Legal professional and education organisations, in collaboration with specialist elder abuse agencies, have important roles in providing training and resources for lawyers across the three screening areas

\footnotetext{
in the United States: Victoria M Rizzo, David Burnes and Amy Chalfy, 'A Systematic Evaluation of a Multidisciplinary Social Work-Lawyer Elder Mistreatment Intervention Model’ (2015) 27(1) Journal of Elder Abuse and Neglect 1. On multidisciplinary team approaches generally: Cynthia Moore and Colette Browne, 'Emerging Innovations, Best Practices, and Evidence-Based Practices in Elder Abuse and Neglect: a Review of Recent Developments in the Field' (2017) 32(4) Journal of Family Violence 383.

${ }^{137}$ Malya Levin and Deirdre Lok, 'Ethics and Elder Abuse: An Attorney's Obligations - Part 1' (2015) 25(2) Elder and Special Needs Law Journal 7, 8.

${ }^{138}$ Xin Qi Dong, 'Development and Validation of a Tool to Improve Physician Identification of Elder Abuse' (n 110), 1692; JK O'Toole and others, 'Resident Confidence Addressing Social History: Is it Influenced by Availability of Social and Legal Resources?’ (2012) 51(7) Clinical Pediatrics 625.
} 
proposed here. Legal regulatory bodies and elder abuse inquiries already highlight the need for improved capacity assessment processes by lawyers. ${ }^{139}$ Interprofessional training that brings together legal and health service providers is particularly valuable to improve practitioners' understanding of each other's roles, to share experiences in screening for elder abuse and assessing capacity, and to establish referral networks. Finally, researchers in legal and health disciplines ought to collaborate with practitioners and involve older people in meaningful ways to design, implement and evaluate elder abuse interventions and build the evidence base to inform effective practices for early detection, action and prevention.

Funding acknowledgement: This work was supported by the Department of Family and Community Services, New South Wales Government, Action on Elder Abuse: A pilot project to improve screening and intervention through health-legal collaboration.

${ }^{139}$ Office of the Legal Services Commission (n 10); NSW Elder Abuse Inquiry (n 3); ALRC Elder Abuse Report (n 8). 